\title{
The glenoid in total shoulder arthroplasty
}

\author{
Mark Schrumpf • Travis Maak • Sommer Hammoud • \\ Edward V. Craig
}

Published online: 9 August 2011

(C) Springer Science+Business Media, LLC 2011

\begin{abstract}
Management of glenohumeral arthrosis with a total shoulder prosthesis is becoming increasingly common. However, failure of the glenoid component remains one of the most common causes for failure. Our understanding of this problem has evolved greatly since the first implants were placed in the 1970's. However glenoid failure remains a challenging problem to address and manage. This article reviews the current knowledge regarding the glenoid in total shoulder arthroplasty touching on anatomy, component design, implant fixation, causes of implant failure, management of glenoid failure and alternatives to glenoid replacement.
\end{abstract}

Keywords Total shoulder arthroplasty - Glenoid component · Hybrid glenoid · Radiolucent lines . Glenoid loosing · Glenoid component failure

\section{Introduction}

Shoulder arthroplasty dates back to 1893 when Jules-Émile Péan, a French surgeon, implanted a platinum and rubber prosthesis to replace a glenohumeral joint that had been

\author{
M. Schrumpf $(\bowtie) \cdot$ T. Maak $\cdot$ S. Hammoud $\cdot$ E. V. Craig \\ Hospital for Special Surgery, \\ 535 E 70th St., \\ New York, NY 10021, USA \\ e-mail: schrumpfm@hss.edu \\ T. Maak \\ e-mail: maakt@hss.edu \\ S. Hammoud \\ e-mail: hammouds@hss.edu \\ E. V. Craig \\ e-mail: craige@hss.edu
}

destroyed by tuberculosis [1]. Very little progress was made in design and function until 1951 when Charles Neer developed an unconstrained Vitallium prosthesis for the treatment of proximal humerus fractures $[2,3]$. Over time Neer sought to develop a shoulder prosthesis that would also afford patients with glenohumeral arthritis pain relief and introduced a glenoid resurfacing component.

Influenced by the success of total hip arthroplasty, Neer developed the first modern total shoulder prosthesis, the Neer II (Smith \& Nephew, Memphis, TN). The Neer II was introduced in 1974 and consisted of a redesigned humeral component and an all-polyethylene glenoid resurfacing component. Over 70 different shoulder prosthetic systems have been developed since the introduction of Neer's initial design in 1974.

Indications for shoulder arthroplasty currently include severe proximal humeral fractures, primary glenohumeral osteoarthritis, post-traumatic arthritis, shoulder girdle tumors, osteonecrosis, and failed shoulder arthroplasty. Although Charles Neer's original prosthesis underwent several modifications, the Neer type humeral component has largely persisted $[2,4-10]$.

\section{Native glenoid anatomy}

Anatomic parameters of the glenoid relevant to prosthesis design and placement include glenoid height, width, inclination, and shape, and version. The considerable natural variability in these parameters, as demonstrated in cadaveric studies, affects prosthesis design, instrumentation, and intraoperative implantation techniques.

The normal glenoid cavity is shaped like an inverted comma, with a narrow upper superior field (the tail of the comma) and a broad inferior field (the head of the comma) 
[11]. Glenoid height is defined as the distance from the most superior and inferior points on the glenoid where as width is the distance from most anterior to posterior points. Mean glenoid height has been reported to range from 35.1 to $39 \mathrm{~mm}$ [12-15]. Churchill et al. and Mallon both reported on gender differences in glenoid size with Churchill concluding that there is an average difference of $4.9 \mathrm{~mm}$ while Mallon concluded that the difference is only $1.8 \mathrm{~mm}[16,17]$. Iannotti et al. reported a mean upper glenoid width of $23 \mathrm{~mm}$ (range, 18-30 mm) and a mean lower glenoid width of $29 \mathrm{~mm}$ (range, 21-35 mm) [14]. Other authors have reported widths ranging from $28.3 \mathrm{~mm}$ to $23.6[13,16,17]$.

Glenoid version is defined as the angular orientation of the axis of the glenoid articular surface relative to the long (transverse) axis of the scapula. Churchill et al. reported that on average the glenoid has $1.2^{\circ}$ of retroversion (range, $9.5^{\circ}$ anteversion- $10.5^{\circ}$ retroversion), while Saha noted that $75 \%$ of shoulders had retroverted glenoids and $25 \%$ were anteverted $[16,18]$.

\section{Patho-anatomy}

Glenoid wear frequently accompanies glenoid arthritis. Walch et al. classified the various glenoid wear patterns in the arthritic glenoid [19]. Posterior subluxation of the humeral head was observed in $45 \%$ of the cases. The main glenoid types were defined as Types A, B, and C. Type A (59\%) features a well-centered humeral head with symmetric erosion and the absence of humeral head subluxation. Type B (32\%) is characterized by posterior humeral head subluxation with a posterior glenoid wear pattern. Type C $(9 \%)$ was defined by glenoid retroversion of more than $25^{\circ}$, regardless of erosion.

Cofield and Matsen have described posterior glenoid wear with varying degrees of posterior subluxation of the humeral head as the most common pattern of glenoid wear for primary osteoarthritis $[20,21]$. An internal rotation contracture often develops as the condition progresses increasing contact of the humeral head with the posterior aspect of the glenoid. Posteriorly worn glenoids are also associated with posterior instability [4, 20, 22, 23].

Glenoid involvement varies with respect to the type of arthritic process affecting the glenohumeral joint [20, 21] Inflammatory arthritis is often associated with central, symmetric glenoid erosion, which may be accompanied by cysts within the glenoid vault [20]. Anterior glenoid erosion may also be encountered, but is much less common. Assessment of extent and location of glenoid wear should be done preoperatively with axillary radiographs, axial CT scans, and 3D CT reconstructions.

The techniques generally used to address nonconcentric glenoid wear include eccentric anterior reaming of the glenoid or the use of bone grafting to correct glenoid version and improve fixation. Augmented glenoid designs have also been proposed [24]. In order to assess the amount of correction that can be achieved with eccentric anterior reaming, Gillespie et al. conducted a cadaveric analysis of 8 specimens [25]. They found that anterior reaming to correct a posterior defect of $10^{\circ}$ resulted in a significant decrease in glenoid diameter $(26.7 \pm 2.5 \mathrm{~mm}$ to $23.8 \pm$ $3.1 \mathrm{~mm}, p=0.006$ ). Furthermore, after correcting for $15^{\circ}$ of posterior bone loss, placement of a glenoid prosthesis was not possible in $50 \%$ of the specimens. Their results led them to recommend bone grafting with defects requiring more than $10^{\circ}$ of anterior correction [25]. Clavert et al., in a similar study, concluded that glenoid retroversion of $15^{\circ}$ or more cannot be satisfactorily corrected simply by reaming to lower the anterior edge of the glenoid and restore neutral version when using a glenoid component with peripheral pegs [26].

\section{Management of the glenoid}

When the decision has been made to replace or resurface the glenoid many choices remain about the best means to achieve long-term pain free shoulder. The anatomy of the glenoid vault makes achieving stable fixation a challenge even in the best circumstances. Implant loosing continues to be a common problem. The options on how to address the glenoid range from biologic solutions to ream and run to polyethylene and metal components. Most traditional total shoulder designs rely on some combination of polyethylene and metal. In the following sections we will review some of the major factors in implant design and placement.

\section{Component types}

There are two major shapes for glenoid component that are currently available - anatomic and oval. There are minimal data demonstrating performance for either type, while both have theoretical advantages. An anatomically shaped glenoid simulates the normal, pear-shaped glenoid. The theoretical advantage of this component design is to avoid internal impingement of soft tissues on the polyethylene component. Nevertheless, this pear shape also reduces the contact surface area and may increase the risk of dislocation [27]. The oval design, on the other hand, mimics the arthritic glenoid and theoretically utilizes the pathologically enlarged glenoid to maximize articular surface area. The increased superior wall height may decrease the risk for dislocation $[28,29]$. 


\section{Glenohumeral implant conformity}

Conformity of the glenohumeral total shoulder articulation has significant impact on the biomechanics of the joint, specifically loading and stability. The degree of conformity is directly related to the relative matching the surface of the glenoid and humeral head components. An equal convexity and concavity will result in a humeral head position that is directly dictated by compression into the glenoid concavity $[21,30]$. The conforming design has the theoretical advantage that it more evenly distributes load to the glenoid. However, this compression constrains the humeral component such that translation cannot occur without glenohumeral separation and edge loading of the glenoid [31]. A number of authors have suggested that a glenoid radius of curvature greater than that of the humeral component ("radial mismatch") may decrease the risk of glenoid loosening [28, 31-37], [38•]. Nho et. al. reported on a retrieval study comparing conforming and nonconforming glenoid components where they showed a loosing score of 3.2 in the conforming group compared to 2.4 in the non-conforming group [38•]. This reduced loosening may be due to a reduction in edge loading.

However a balance must be achieved between over- and under-conforming articulations, as prior data have documented increased polyethylene wear, fracture and decreased joint stability with minimally conforming designs [31]. Walch et al. evaluated radiolucent lines and Constant scores in 319 TSAs with four different radial mismatch groups [31]. The groups studied were: $<4 \mathrm{~mm}, 4.5-5.5 \mathrm{~mm}, 6-$ $7 \mathrm{~mm}$, and 7-10 $\mathrm{mm}$. The fewest radiolucent lines were seen in the 7-10 mm group and the highest mean Constant scores were documented in the 6-7 $\mathrm{mm}$ group. These data led the authors to conclude that the optimal radial mismatch both clinically and radiographically is $6-7 \mathrm{~mm}$.

\section{Component fixation}

The techniques that have been described to fix the glenoid component include cemented all poly components with keels and pegs, metal backed components with and without in-growth designs, screws and finally hybrid designs that use both cemented poly and in-growth metal [39]. No one single fixation modality has become the standard method, reflecting the continued interest in developing a more durable construct with greater implant longevity.

\section{Clinical results for glenoid replacement}

Optimizing component design has been extensively studied through many retrospective studies. The experience of the
Mayo Clinic was recently reviewed for six different of implant designs placed at the same institution over 20 years [40••]. These included the Neer II all poly, Neer II metalbacked, Cofield I metal backed in-growth (Smith \& Nephew, Memphis, TN), Cofield I all poly, Cofield II all poly keeled and Cofield II all poly pegged (Smith \& Nephew, Memphis, TN). One hundred twenty-five shoulders were revised due to glenoid failure. Survival rates for the different designs ranged from $95 \%$ to $67 \%$. The authors concluded that glenoid component type was significantly associated with revision. The poorest survival seen for the Cofield 1 metal backed components while the best results were seen with the all Poly Neer II.

In another comparison between metal backed implants and all poly keeled components Boileau et al. performed a prospective randomized controlled study using the same system with two different glenoid designs [41]. Forty shoulders were randomized to keeled vs metal backed designs with expansion screws. At 3 year follow up the authors documented a $20 \%$ failure of the metal group vs $0 \%$ in the keeled group. Additional studies have also found troublingly high rates of both clinical and radiographic failure for metal backed components. Taunton, et al. studied metal backed glenoid components with a mean 9.5-year follow-up. The documented five-year survival of $79.9 \%$ and ten-year survival of $51.9 \%$ led the authors to raise significant concerns regarding the use of metal backed, non-cemented glenoid components [42•].

Alternatively, better results have been reported for some metal backed designs. Specifically, Clement et al. showed a $91.7 \% 5$ year survival and a $89 \% 10$ year survival in rheumatoid patients using the Bio-modular (Biomet Warsaw, Indiana) implant [43]. They posited that the use of a screw construct, a fully coated bone in-growth surface at the bone interface and a low profile tray were critical factors in their improved survival. Likewise Castagna reported promising results in a series of 35 glenoids stabilized with screws and a large hallow central peg with a bone in-growth surface [44]. They had no patients who needed revision of their glenoid components during their follow up.

\section{Cemented all poly designs}

The experience with metal backed designs can at best be described as mixed. An alternative to metal backed designs is a traditional all poly cemented design. This style of glenoid implant has been used for many years with good clinical success. The first total shoulder arthroplasty implanted by Dr. Neer in the early 1970's used an all poly keeled cemented component. He observed no loosing the glenoid component; though he only had 37 months of 
follow up and he observed $30 \%$ rate of lucent lines the majority of which were seen on the initial post operative x-rays [4]. Similar results have been shown by Cofield who showed $19.2 \%$ of glenoids 2 weeks after implantation had lucent lines and an additional $31.5 \%$ develop in the first 2 months [5].

Gartsman et al. prospectively compared pegged and keeled components and documented periprosthetic radiolucency in $39 \%$ of keeled components, as compared to only $5 \%$ of pegged components at 6 week follow-up [45]. Moreover, the extent of radiolucency was greater with the keeled components. Prior two-year follow-up data has demonstrated that keeled components experienced significantly increased translation and rotation, as compared to pegged components [46].

In addition to pegs and keels component fixation is also influenced by the geometry of the glenoid component-bone articulation. Flat and curve-backed cemented components have been studied in this regard. Two-year follow-up radiographic data from 66 TSAs documented optimal component seating in $65 \%$ of curved back, as compared to $26 \%$ of flat-back components [47]. Moreover, at final follow-up, increased radiolucency was documented in flatbacked components. These data were further substantiated by laboratory and finite element analyses that documented both reduced distraction and peak strains with curved-back glenoid components [22, 32].

One explanation for the observed early radiolucency has been offered by Churchill. They posit that the heat generated with the exothermic reaction during the curing of poplymethylmethacrylate cement is responsible for bone necrosis [48]. They showed that during curing of the cement that the temperature reached an average of $64.7^{\circ}$ Centigrade. These observed temperatures were well in excess of the $56^{\circ}$ Centigrade known to cause bone necrosis.

An alternative explanation for the lucency is cementing technique. "Modern" technique has been shown to improve radiographic results but the exact definition of modern technique remains somewhat unclear. A number of authors including Norris, Mileti and Kasten have all written on the "modern" technique for fixation though there is considerable variation in what that means [49-51]. Common elements to modern technique include lavage and drying of the vault and cement pressurization into the glenoid with a syringe [52].

\section{Hybrid glenoid}

As an alternative to either a metal backed component or an all poly cemented glenoid the senior author (EVC) prefers to use a hybrid glenoid. Hybrid fixation is a combination of the two main forms of fixation, cemented and metal backed in-growth [39]. Our preferred component for primary osteoarthritis uses 3 outer pegs with a porous titanium ingrowth central peg [See Fig. 1]. We believe that this design combines the benefits of a cemented all poly pegged construct with multiple points of immediate fixation that resist sheer forces and the feature of long term incorporation with an in-growth metal peg. We feel that with good incorporation of the porous central peg the issues that have been observed with osteolysis and loosing over the long term will be avoided. Additionally, the outer cemented pegs with their ability to immediately resist sheer forces allow for a stable environment where solid bony incorporation can occur along the central in-growth peg. Preliminary data from this glenoid has shown improved clinical scores for both UCLA and SST, and range of motion at 2 year follow up on 54 shoulders [53]. Further along the central bone in-growth peg there were no lucencies greater than $1 \mathrm{~mm}$ [53]. All of the titanium porous in-growth implants showed radiographic evidence of incorporation by 1 year [53]. Finally, at 2 year follow up no patients showed either clinically significant or progressive lucency though longer follow up is clearly needed [53].

One additional author has published on a glenoid component which also uses a combination of minimal cement and biologic incorporation. Their implant uses radial fins on the central peg that are packed with bone graft from the glenoid reaming and peripherally cemented pegs [54]. They used CT scans to evaluate the bone implant

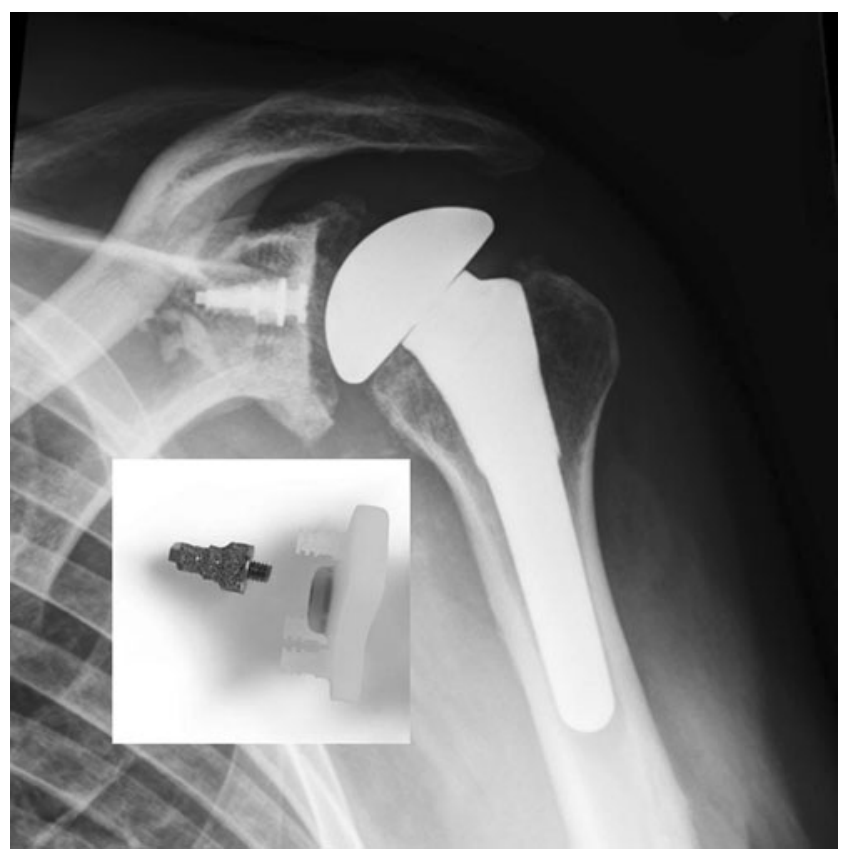

Fig. 1 Preferred glenoid implant of the senior author (EVC) using a titanium pourous ingrowth central peg with 3 outer pegs fixed with cement. Radiograph shows incorporation of the central peg at 2 year follow up 
interface in 35 patients, they were able to show bone between the fins in a six compartments in $23 / 35$ shoulders and on average 4.5/6 compartments had bone. By plain radiographs the mean Lazarus radiolucency scores were 0.45 at 43 months. A similar study with promising results was also recently reported by Churchill with 5 year follow up, though CT scans were not used to evaluate the bone implant interface [55]. The use of minimally cemented glenoid components with some form of in-growth potential is an exciting trend in glenoid fixation. We will have to await more data before the efficacy of this hybrid concept can be fully determined.

\section{Long term complications}

Glenoid failure can be broken down into a number of distinct categories. These include component failure, inadequate seating the component, failure of fixation, and osteolysis. Glenoid loosing can drive many symptoms including increased pain, decreased shoulder function and may eventually lead to the need for revision surgery. Loosing occurs in as many as $96 \%$ percent of implanted glenoids if we assume that lucent lines are indicative of loosening [39]. The rate of revision due to symptomatic loosing is significantly lower, however the rate is still troublingly high with published rates as high as $13 \%[40 \bullet \cdot]$.

Component failure is typified by changes in the poly portion of the component after implantation. These changes include pitting and third body wear which has been shown to be associated with osteolysis [56]. Additionally, cold flow and wear contribute to the thinning and eventual failure of the poly in the glenoid components [57]. Catastrophic failure of the poly can occur from these processes though they are more commonly associated with sterilization by radiation in air [58].

When the bone stock of the glenoid has not been adequately prepared or when the component fails to fully seat on the surface the risk of micromotion, fatigue and eventual clinical loosing is significant. It has been shown that when the surface has been prepared thoroughly and the component seats the risk of wobble and warp are minimized [29]. In a clinical series of 328 glenoids Lazarus showed that $1 / 3$ were poorly seated. Further they showed that the keeled implants seated more poorly than the pegged versions [59].

Matsen has popularized the concept of "the rocking horse glenoid" phenomenon which is believed to be a significant source of glenoid loosing [60]. The phenomenon is caused by eccentric loading on one edge of the component causing the opposite edge to lift off the glenoid bone. This mechanism is thought to lead to loosening in the setting of rotator cuff tears as well as component mal positioning. Component positioning primarily varies in a superior-inferior dimension such that placement of the glenoid or humeral components in suboptimal positions may increase the risk of glenoid edge loading and the resultant "rocking horse" phenomenon. Farron reported on a finite element analysis that lends credence to Matsen's rocking horse theory [61]. They showed that glenoid retroversion lead to a $700 \%$ increase in micro-motion and a $326 \%$ increase in stress at the bone-cement interface compared to neutrally oriented components. Hopkins also reported on a finite element analysis examining the role of implant position on stability. Those implanted centrally had the lowest potential for failure. Where as those implanted superiorly or inferiorly inclined have the greatest potential for failure [62].

Rotator cuff insufficiency also leads to eccentric loading and the rocking horse phenomenon. Anteroposterior eccentric loading can occur with massive subscapularis ruptures, or more commonly, failure of the operative repair of the subscapularis [63-65]. Massive supraspinatus and infraspinatus insufficiency can produce superior migration of the humeral component producing a relative malpositioning and eccentric loading of the glenoid [9, 29, 32, 60, 66, 67].

In addition to poor seating, eccentric loading, and failure of the poly, resorption of the bony support for the glenoid also leads to implant failure. As has been well documented, radiolucent lines are commonly seen at the bone cement interface in many glenoid components [39, 40••, 42•, 44, $48,50,51,54,55,57,60,62]$. The postulated causes of this bone loss are motion, heat induced necrosis, and infection. Kepler has shown that osteolysis is most associated with screw fixation of the glenoid component and third body ware [56]. When the loss becomes extreme it may result of the loss stability of the glenoid component.

\section{Predictors of failure}

Some authors have isolated predictive factors that lead to glenoid failure. In one series of mid to long term follow-up Fox et. al. were able to show that in addition to specific implants with poorer track records, male gender, and posttraumatic or avascular necrosis (as opposed to degenerative arthritis) lead to increased rates of revision [40 • ]. In their multiple regression analysis male gender had a hazard ratio (HR) of 2.2, post-traumatic arthritis had a HR of 1.8 and avascular necrosis had a HR of 2.7. Additionally, it has been observed that patients with deficient rotator cuffs have increased rates of glenoid failure, as well as glenohumeral instability [57, 60]. One final group of patients who are observed to have increased rates of failure are those patients who rely on their upper extremities for ambulation (through the use of a cane or crutches) [57]. 


\section{Managing a failed glenoid}

When deciding to attempt to manage a loose glenoid, one has a number of choices which range from arthroscopic removal of the component to complete revision with structural allograft of the glenoid vault. The least invasive option is to remove the glenoid component via arthroscopic methods. When the component is frankly loose it can be extracted through an enlarged anterior portal $[68,69]$. The component can be removed whole or moralized. In some cases removal of the loose component can adequately address the symptoms. As Antuna described in their 4.9 year follow up of shoulders that underwent revision glenoid surgery, $66 \%$ of patients had satisfactory pain relief with removal alone [63]. However this same study also revealed a greater rate of success in those patients who underwent reimplanation where the authors observed $86 \%$ pain relief. Raphael et al. addressed a similar series of patients with symptomic loose glenoid components [69]. They noted that while functional scores were slightly higher in the reimplantation group, patient satisfaction was equally high in both the resection and reimplantation groups.

Prior to placing a new glenoid component the remaining vault must be accessed. This is best accomplished via a $\mathrm{CT}$ scan with 3-D reconstructions [70]. If there is inadequate bone, grafting can be performed with canellous graft in a two stage procedure as described by Cheung [71]. If there is a large cavitary defect with loss of the wall of the glenoid vault a structural allograft is likely indicated where bulk femoral head is contoured to the defect [72]. It is necessary to use these structural grafts when the wall is compromised as cancallous graft cannot be contained in these cases.

Clinically a number of authors have all found that reimplantation of a glenoid component provides superior results to resection of the failed glenoid component alone $[63,69,71,73]$. The improvements include greater relief of pain and increased external rotation.

\section{Other resurfacing options}

Significant challenges exist in the setting of poor glenoid bone stock or glenohumeral arthrosis in young patients. In these settings, placement of a prosthetic glenoid component may not be a favorable option. Fortunately, other resurfacing options exist including the "ream-and-run" procedure and biologic resurfacing.

\section{Ream-and-run procedure}

Concentric reaming of the glenoid to a radius of curvature of 1 to $2 \mathrm{~mm}$ greater then the prosthetic humeral head component has been termed the "ream-and-run" procedure [74]. This concentric reaming is designed to re-contour the glenoid to improve glenohumeral stability and reduce the eccentric erosion and subsequent instability that has been previously associated with isolated humeral hemiarthroplasty [75]. Prior data has documented healing and glenoid remodeling potential following the ream-and-run procedure [76]. In addition, cadaveric model biomechanical data demonstrated increased glenohumeral stability following the ream-and-run procedure, as compared to a glenoid with denuded articular cartilage [77]. While some data suggest favorable outcomes following this procedure, in the current authors' opinion, this procedure should be reserved for use only in the setting of salvage, as results that have been reported for the short and mid term have been inconsistent.

\section{Biologic resurfacing}

Biologic resurfacing has been employed primarily in the setting of younger patients. Many different types of interposition graft resurfacing have been attempted including joint capsule, fascia lata, Achilles tendon allograft, lateral meniscal allograft, and processed human dermis (GraftJacket, Wright Medical Ltd, Arlington, TN, USA) [78]. These methods are used in concert with placement of a humeral hemiarthroplasty in an attempt to eliminate both the high failure risk of the glenoid component in TSA and the poor or inconsistent outcomes that have been associated with hemiarthroplasty alone $[79,80]$.

Long term follow-up data with mixed interpositional graft types demonstrated excellent, satisfactory and unsatisfactory results in 18, 13 and five out of 36 shoulders, respectively [81]. The authors identified re-injury, infection, and use of capsule as interposition material as the causes of unsatisfactory results. Additionally, they identified Achilles tendon allograft as leading to excellent to satisfactory results. Additional data using lateral meniscal allograft resurfacing has documented improvements in ASES scores from 38 to 69 at eighteen-month follow-up [3]. However a $17 \%$ revision rate was documented in the first postoperative year. Savoie et al. documented statistically significant improvements for young patients with arthroscopic glenoid resurfacing with the Restore patch (Restore, DePuy Orthopaedics, Warsaw, IN, USA) at three to six-year follow-up [82]. Other data from capsule, fascia lata and Achilles tendon interposition grafts demonstrated ASES mean improvement scores from 39 to 91 at a mean sevenyear follow-up [81]. Similar to prior studies, anterior capsule interposition graft was associated with poor results $[22,83]$. These data led the authors to recommend Achilles tendon allograft as the best option. 
Elhassan et al., however, studied 13 patients with a mean age of 36 years, 11 of which were treated with Achilles tendon allograft glenoid resurfacing [84.•]. 77\% of patients required revision to TSA at a mean of 14 months due to pain and decreased range of motion. Therefore, these authors concluded that Achilles allograft glenoid resurfacing was not a reliable method of treatment in the young, active patient. It is also the senior authors' (EVC) experience that biologic glenoid resurfacing does not produce satisfactory outcomes and thus primary resurfacing of the glenoid should be performed whenever possible.

\section{Conclusion}

Arthrosis of the glenoid continues to offer challenges to the treating surgeon. The glenoid with its variable anatomy, minimal bone stock and inherent instability makes addressing the glenoid one the most difficult procedures in orthopedics. The continuing evolution of implant design offers the hope that we will be able to achieve a stable, long lasting and predictable solution to glenoid resurfacing for patients of all ages. In the mean time understanding and managing failed glenoid components provides the shoulder surgeon with challenges that continue to fuel future implant design.

Disclosures M. Schrumpf: none; T. Maak: none; S. Hammoud: none; E. Craig: consultant to Biomet, Inc. for shoulder prosthesis, receives royalties from Biomet, Inc. for shoulder prosthesis.

\section{References}

Papers of particular interest, published recently, have been highlighted as:

- Of importance

•- Of major importance

1. Lugli T. Artificial shoulder joint by Pean (1893): the facts of an exceptional intervention and the prosthetic method. Clin Orthop Relat Res. 1978;133:2158

2. Neer II CS. Articular replacement for the humeral head. J Bone Joint Surg Am. 1955;37-A(2):215-28.

3. Nicholson GP, Goldstein JL, Romeo AA, Cole BJ, Hayden JK, Twigg SL, et al. Lateral meniscus allograft biologic glenoid arthroplasty in total shoulder arthroplasty for young shoulders with degenerative joint disease. J Shoulder Elbow Surg. 2007;16 (5 Suppl):S261-6.

4. Neer II CS, Watson KC, Stanton FJ. Recent experience in total shoulder replacement. J Bone Joint Surg Am. 1982;64(3):319-37.

5. Cofield RH. Total shoulder arthroplasty with the Neer prosthesis. J Bone Joint Surg Am. 1984;66(6):899-906.

6. Gartsman GM, Roddey TS, Hammerman SM. Shoulder arthroplasty with or without resurfacing of the glenoid in patients who have osteoarthritis. J Bone Joint Surg Am. 2000;82(1):26-34.
7. Gartsman GM, Russell JA, Gaenslen E. Modular shoulder arthroplasty. J Shoulder Elbow Surg. 1997;6(4):333-9.

8. Matsen III FA. Early effectiveness of shoulder arthroplasty for patients who have primary glenohumeral degenerative joint disease. J Bone Joint Surg Am. 1996;78(2):260-4.

9. Norris TR, Iannotti JP. Functional outcome after shoulder arthroplasty for primary osteoarthritis: a multicenter study. J Shoulder Elbow Surg. 2002;11(2):130-5.

10. Wallace AL, Phillips RL, MacDougal GA, Walsh WR, Sonnabend DH. Resurfacing of the glenoid in total shoulder arthroplasty. A comparison, at a mean of 5 years, of prostheses inserted with and without cement. J Bone Joint Surg Am. 1999;81(4):510-8.

11. DePalma AF, Callery G, Bennett GA. Shoulder joint: variational anatomy and degenerative lesions of the shoulder joint. Instr Course Lect. 1949;6:255-81.

12. Checroun AJ, Hawkins C, Kummer FJ, Zuckerman JD. Fit of current glenoid component designs: an anatomic cadaver study. J Shoulder Elbow Surg. 2002;11(6):614-7.

13. Kwon YW, Powell KA, Yum JK, Brems JJ, Iannotti JP. Use of three-dimensional computed tomography for the analysis of the glenoid anatomy. J Shoulder Elbow Surg. 2005;14(1):85-90.

14. Iannotti JP, Gabriel JP, Schneck SL, Evans BG, Misra S. The normal glenohumeral relationships. An anatomical study of one hundred and forty shoulders. J Bone Joint Surg Am. 1992;74 (4):491-500.

15. Sharkey NA, Marder RA. The rotator cuff opposes superior translation of the humeral head. Am J Sports Med. 1995;23 (3):270-5.

16. Churchill RS, Brems JJ, Kotschi H. Glenoid size, inclination, and version: an anatomic study. J Shoulder Elbow Surg. 2001;10 (4):327-32.

17. Mallon WJ, Brown HR, Vogler III JB, Martinez S. Radiographic and geometric anatomy of the scapula. Clin Orthop Relat Res. 1992;277:142-54.

18. Saha AK. The classic. Mechanism of shoulder movements and a plea for the recognition of "zero position" of glenohumeral joint. Clin Orthop Relat Res. 1983;173:3-10.

19. Walch G, Boulahia A, Boileau P, Kempf JF. Primary glenohumeral osteoarthritis: clinical and radiographic classification. The Aequalis Group. Acta Orthop Belg. 1998;64 Suppl 2:46-52.

20. Cofield RH, Edgerton BC. Total shoulder arthroplasty: complications and revision surgery. Instr Course Lect. 1990;39:449-62.

21. Matsen III FA, Bicknell RT, Lippitt SB. Shoulder arthroplasty: the socket perspective. J Shoulder Elbow Surg. 2007;16(5 Suppl): S241-7.

22. Iannotti JP, Spencer EE, Winter U, Deffenbaugh D, Williams G. Prosthetic positioning in total shoulder arthroplasty. J Shoulder Elbow Surg. 2005;14(1 Suppl S):111S-21S.

23. Moeckel BH, Altchek DW, Warren RF, Wickiewicz TL, Dines DM. Instability of the shoulder after arthroplasty. J Bone Joint Surg Am. 1993;75(4):492-7.

24. Rice RS, Sperling JW, Miletti J, Schleck C, Cofield RH. Augmented glenoid component for bone deficiency in shoulder arthroplasty. Clin Orthop Relat Res. 2008;466(3):579-83.

25. Gillespie R, Lyons R, Lazarus M. Eccentric reaming in total shoulder arthroplasty: a cadaveric study. Orthopedics. 2009;32 (1):21.

26. Clavert P, Millett PJ, Warner JJ. Glenoid resurfacing: what are the limits to asymmetric reaming for posterior erosion? J Shoulder Elbow Surg. 2007;16(6):843-8.

27. Williams GR, Abboud JA. Total shoulder arthroplasty: glenoid component design. J Shoulder Elbow Surg. 2005;14(1 Suppl S): $122 \mathrm{~S}-8 \mathrm{~S}$.

28. Anglin C, Wyss UP, Nyffeler RW, Gerber C. Loosening performance of cemented glenoid prosthesis design pairs. Clin Biomech (Bristol, Avon). 2001;16(2):144-50. 
29. Collins D, Tencer A, Sidles J, Matsen III F. Edge displacement and deformation of glenoid components in response to eccentric loading. The effect of preparation of the glenoid bone. J Bone Joint Surg Am. 1992;74(4):501-7.

30. Anglin C, Wyss UP, Pichora DR. Shoulder prosthesis subluxation: theory and experiment. J Shoulder Elbow Surg. 2000;9 (2):104-14.

31. Walch G, Edwards TB, Boulahia A, Boileau P, Mole D, Adeleine $\mathrm{P}$. The influence of glenohumeral prosthetic mismatch on glenoid radiolucent lines: results of a multicenter study. J Bone Joint Surg Am. 2002;84-A(12):2186-91.

32. Anglin C, Wyss UP, Pichora DR. Mechanical testing of shoulder prostheses and recommendations for glenoid design. J Shoulder Elbow Surg. 2000;9(4):323-31.

33. Couteau B, Mansat P, Estivalezes E, Darmana R, Mansat M, Egan J. Finite element analysis of the mechanical behavior of a scapula implanted with a glenoid prosthesis. Clin Biomech (Bristol, Avon). 2001;16(7):566-75.

34. Karduna AR, Williams GR, Iannotti JP, Williams JL. Total shoulder arthroplasty biomechanics: a study of the forces and strains at the glenoid component. J Biomech Eng. 1998;120 (1):92-9.

35. Karduna AR, Williams GR, Williams JL, Iannotti JP. Glenohumeral joint translations before and after total shoulder arthroplasty. A study in cadavera. J Bone Joint Surg Am. 1997;79(8):1166-74.

36. Severt R, Thomas BJ, Tsenter MJ, Amstutz HC, Kabo JM. The influence of conformity and constraint on translational forces and frictional torque in total shoulder arthroplasty. Clin Orthop Relat Res. 1993;292:151-8.

37. Terrier A, Buchler P, Farron A. Influence of glenohumeral conformity on glenoid stresses after total shoulder arthroplasty. J Shoulder Elbow Surg. 2006;15(4):515-20.

38. - Nho SJ, Ala OL, Dodson CC, Figgie MP, Wright TM, Craig EV, et al. Comparison of conforming and nonconforming retrieved glenoid components. J Shoulder Elbow Surg. 2008;17(6):914-20. This paper reaffirmed through retrieval data that conforming glenoids show greater wear.

39. Strauss EJ, Roche C, Flurin PH, Wright T, Zuckerman JD. The glenoid in shoulder arthroplasty. J Shoulder Elbow Surg. 2009;18 (5):819-33.

40. •- Fox TJ, Cil A, Sperling JW, Sanchez-Sotelo J, Schleck CD, Cofield RH. Survival of the glenoid component in shoulder arthroplasty. J Shoulder Elbow Surg. 2009;18(6):859-63. This paper presented good 20 year follow up data on a number of implant designs and was large enough to isolate risk factors for early loosing.

41. Boileau P, Avidor C, Krishnan SG, Walch G, Kempf JF, Mole D. Cemented polyethylene versus uncemented metal-backed glenoid components in total shoulder arthroplasty: a prospective, double-blind, randomized study. J Shoulder Elbow Surg. 2002;11(4):351-9.

42. - Taunton MJ, McIntosh AL, Sperling JW, Cofield RH. Total shoulder arthroplasty with a metal-backed, bone-ingrowth glenoid component. Medium to long-term results. J Bone Joint Surg Am. 2008;90(10):2180-8. This paper shows the high rates of failure of metal backed designs.

43. Clement ND, Mathur K, Colling R, Stirrat AN. The metal-backed glenoid component in rheumatoid disease: eight- to fourteen-year follow-up. J Shoulder Elbow Surg. 2010;19(5):749-56.

44. Castagna A, Randelli M, Garofalo R, Maradei L, Giardella A, Borroni M. Mid-term results of a metal-backed glenoid component in total shoulder replacement. J Bone Joint Surg Br. 2010;92 (10):1410-5.

45. Gartsman GM, Elkousy HA, Warnock KM, Edwards TB, O'Connor DP. Radiographic comparison of pegged and keeled glenoid components. J Shoulder Elbow Surg. 2005;14(3):252-7.
46. Nuttall D, Haines JF, Trail II. A study of the micromovement of pegged and keeled glenoid components compared using radiostereometric analysis. J Shoulder Elbow Surg. 2007;16(3 Suppl): S65-70.

47. Szabo I, Buscayret F, Edwards TB, Nemoz C, Boileau P, Walch G. Radiographic comparison of flat-back and convex-back glenoid components in total shoulder arthroplasty. J Shoulder Elbow Surg. 2005;14(6):636-42.

48. Churchill RS, Boorman RS, Fehringer EV, Matsen III FA. Glenoid cementing may generate sufficient heat to endanger the surrounding bone. Clin Orthop Relat Res. 2004;419:76-9.

49. Kasten P, Pape G, Raiss P, Bruckner T, Rickert M, Zeifang F, et al. Mid-term survivorship analysis of a shoulder replacement with a keeled glenoid and a modern cementing technique. J Bone Joint Surg Br. 2010;92(3):387-92.

50. Mileti J, Boardman III ND, Sperling JW, Cofield RH, Torchia ME, O'driscoll SW, et al. Radiographic analysis of polyethylene glenoid components using modern cementing techniques. J Shoulder Elbow Surg. 2004;13(5):492-8.

51. Norris BL, Lachiewicz PF. Modern cement technique and the survivorship of total shoulder arthroplasty. Clin Orthop Relat Res. 1996;328:76-85.

52. Young AA, Walch G. Fixation of the glenoid component in total shoulder arthroplasty: what is "modern cementing technique?". J Shoulder Elbow Surg. 2010;19(8):1129-36.

53. Dines DM, Dines JS, Warren RF, Craig EV, Gulotta L. Early results of hybrid glenoid replacement in TSA for osteoarthritis. Scotland: Edinburgh; 2010.

54. Arnold RM, High RR, Grosshans KT, Walker CW, Fehringer EV. Bone presence between the central peg's radial fins of a partially cemented pegged all poly glenoid component suggest few radiolucencies. J Shoulder Elbow Surg. 2011;20(2):315-21.

55. Churchill RS, Zellmer C, Zimmers HJ, Ruggero R. Clinical and radiographic analysis of a partially cemented glenoid implant: five-year minimum follow-up. J Shoulder Elbow Surg. 2010;19 (7):1091-7.

56. Kepler CK, Nho SJ, Bansal M, Ala OL, Craig EV, Wright TM, et al. Radiographic and histopathologic analysis of osteolysis after total shoulder arthroplasty. J Shoulder Elbow Surg. 2010;19 (4):588-95.

57. Matsen III FA, Clinton J, Lynch J, Bertelsen A, Richardson ML. Glenoid component failure in total shoulder arthroplasty. J Bone Joint Surg Am. 2008;90(4):885-96.

58. Rockwood Jr CA, Wirth MA. Observation on retrieved Hylamer glenoids in shoulder arthroplasty: problems associated with sterilization by gamma irradiation in air. J Shoulder Elbow Surg. 2002;11(2):191-7.

59. Lazarus MD, Jensen KL, Southworth C, Matsen III FA. The radiographic evaluation of keeled and pegged glenoid component insertion. J Bone Joint Surg Am. 2002;84-A(7):1174-82.

60. Franklin JL, Barrett WP, Jackins SE, Matsen III FA. Glenoid loosening in total shoulder arthroplasty. Association with rotator cuff deficiency. J Arthroplasty. 1988;3(1):39-46.

61. Farron A, Terrier A, Buchler P. Risks of loosening of a prosthetic glenoid implanted in retroversion. J Shoulder Elbow Surg. 2006;15(4):521-6.

62. Hopkins AR, Hansen UN, Amis AA, Emery R. The effects of glenoid component alignment variations on cement mantle stresses in total shoulder arthroplasty. J Shoulder Elbow Surg. 2004;13(6):668-75.

63. Antuna SA, Sperling JW, Cofield RH, Rowland CM. Glenoid revision surgery after total shoulder arthroplasty. J Shoulder Elbow Surg. 2001;10(3):217-24.

64. Green A, Norris TR. Shoulder arthroplasty for advanced glenohumeral arthritis after anterior instability repair. J Shoulder Elbow Surg. 2001;10(6):539-45. 
65. Sperling JW, Antuna SA, Sanchez-Sotelo J, Schleck C, Cofield RH. Shoulder arthroplasty for arthritis after instability surgery. J Bone Joint Surg Am. 2002;84-A(10):1775-81.

66. Arntz CT, Matsen III FA, Jackins S. Surgical management of complex irreparable rotator cuff deficiency. J Arthroplasty. 1991;6 (4):363-70.

67. Hopkins AR, Hansen UN, Amis AA, Taylor M, Emery RJ. Glenohumeral kinematics following total shoulder arthroplasty: a finite element investigation. J Orthop Res. 2007;25(1):108-15.

68. O'Driscoll SW, Petrie RS, Torchia ME. Arthroscopic removal of the glenoid component for failed total shoulder arthroplasty. A report of five cases. J Bone Joint Surg Am. 2005;87(4):858-63.

69. Raphael BS, Dines JS, Warren RF, Figgie M, Craig EV, Fealy S, et al. Symptomatic glenoid loosening complicating total shoulder arthroplasty. HSS J. 2010;6(1):52-6.

70. Codsi MJ, Bennetts C, Gordiev K, Boeck DM, Kwon Y, Brems J, et al. Normal glenoid vault anatomy and validation of a novel glenoid implant shape. J Shoulder Elbow Surg. 2008;17(3):471-8.

71. Cheung EV, Sperling JW, Cofield RH. Reimplantation of a glenoid component following component removal and allogenic bonegrafting. J Bone Joint Surg Am. 2007;89(8):1777-83.

72. Scalise JJ, Iannotti JP. Bone grafting severe glenoid defects in revision shoulder arthroplasty. Clin Orthop Relat Res. 2008;466 (1):139-45.

73. Deutsch A, Abboud JA, Kelly J, Mody M, Norris T, Ramsey ML, et al. Clinical results of revision shoulder arthroplasty for glenoid component loosening. J Shoulder Elbow Surg. 2007;16 (6):706-16.

74. Clinton J, Franta AK, Lenters TR, Mounce D, Matsen III FA. Nonprosthetic glenoid arthroplasty with humeral hemiarthroplasty and total shoulder arthroplasty yield similar self-assessed outcomes in the management of comparable patients with glenohumeral arthritis. J Shoulder Elbow Surg. 2007;16(5):534-8.

75. Hasan SS, Leith JM, Campbell B, Kapil R, Smith KL, Matsen III FA. Characteristics of unsatisfactory shoulder arthroplasties. J Shoulder Elbow Surg. 2002;11(5):431-41.
76. Matsen III FA, Clark JM, Titelman RM, Gibbs KM, Boorman RS, Deffenbaugh D, et al. Healing of reamed glenoid bone articulating with a metal humeral hemiarthroplasty: a canine model. J Orthop Res. 2005;23(1):18-26.

77. Weldon III EJ, Boorman RS, Smith KL, Matsen III FA. Optimizing the glenoid contribution to the stability of a humeral hemiarthroplasty without a prosthetic glenoid. J Bone Joint Surg Am. 2004;86-A(9):2022-9.

78. Burkhead Jr WZ, Krishnan SG, Lin KC. Biologic resurfacing of the arthritic glenohumeral joint: Historical review and current applications. J Shoulder Elbow Surg. 2007;16(5 Suppl):S248-53.

79. Bohsali KI, Wirth MA, Rockwood Jr CA. Complications of total shoulder arthroplasty. J Bone Joint Surg Am. 2006;88 (10):2279-92.

80. Edwards TB, Kadakia NR, Boulahia A, Kempf JF, Boileau P, Nemoz C, et al. A comparison of hemiarthroplasty and total shoulder arthroplasty in the treatment of primary glenohumeral osteoarthritis: results of a multicenter study. J Shoulder Elbow Surg. 2003;12(3):207-13.

81. Krishnan SG, Nowinski RJ, Harrison D, Burkhead WZ. Humeral hemiarthroplasty with biologic resurfacing of the glenoid for glenohumeral arthritis. Two to fifteen-year outcomes. J Bone Joint Surg Am. 2007;89(4):727-34.

82. Savoie III FH, Brislin KJ, Argo D. Arthroscopic glenoid resurfacing as a surgical treatment for glenohumeral arthritis in the young patient: midterm results. Arthroscopy. 2009;25(8):864-71.

83. Hettrich CM, Weldon III E, Boorman RS, Parsons IV IM, Matsen FA. Preoperative factors associated with improvements in shoulder function after humeral hemiarthroplasty. J Bone Joint Surg Am. 2004;86-A(7):1446-51.

84. •• Elhassan B, Ozbaydar M, Diller D, Higgins LD, Warner JJ. Soft-tissue resurfacing of the glenoid in the treatment of glenohumeral arthritis in active patients less than 50 years old. J Bone Joint Surg Am. 2009;91(2):419-24. This paper clearly showed that biologic resurfacing has a high failure rate and is not the panacea for the young patient with shoulder arthrosis. 